\title{
Tenosinovitis por Pseudomonas Aeruginosa del extensor común de los dedos tras tatuaje
}

\author{
Pérez $\mathrm{N}^{1^{*}}$, Zlatkes $\mathrm{JS}^{1}$, Sánchez $\mathrm{M}^{2}$, Buendía $\mathrm{D}^{3}$, Guillén Astete $\mathrm{CA}^{1}$, Dronda $\mathrm{F}^{2}$ \\ 1. Urgencias. Hospital Universitario Ramón y Cajal. 2. E. Infecciosas. Hospital Universitario Ramón y Cajal. \\ 3. Dermatología. Hospital Universitario Ramón y Cajal. \\ *Correspondencia: nuriaperezortiz@gmail.com
}

\section{Resumen}

Presentamos un caso de una tenosinovitis infecciosa del tendón extensor común de los dedos en un adulto joven que consultó en urgencias por dolor, tumefacción e impotencia funcional tras hacerse un tatuaje en el pie izquierdo dos meses antes.

\section{Palabras clave:}

Tenosinovitis, tatuaje, pseudomonas aeruginosa, tendón extensor común de los dedos.

\begin{abstract}
A case is presented of an infectious tenosynovitis of extensor digitorum tendon in a young women who arrived in the Emergency unit due to tender, pain and swelling after getting a tattoo on her left foot two months before.
\end{abstract}

\section{Keywords}

Tenosynovitis, tatoo, pseudomonas aeruginosa, commun extensor of the fingers.

\section{Introducción}

La tenosinovitis se define como una inflamación de la vaina que rodea a un tendón. Sus causas más frecuentes son las traumáticas, infecciosas, inflamatorias y con menos prevalencia, la afectación tumoral. [1, 2, 3]

En el caso de la tenosinovitis infecciosa, los patógenos más frecuentes son la flora de la piel [cocos gram positivos como Staphylococus aureus y streptococus]. El microorganismo puede entrar en la vaina del tendón directamente por inoculación por traumatismo o por propagación de los tejidos blandos adyacentes infectados. También es posible la vía hematógena. $[4,5]$

\section{Observación clínica}

Mujer de 24 años, sin antecedentes de interés, que consultó por lesión cutánea, dolor e impotencia funcional en el pie izquierdo. Los síntomas de 2 meses de evolución que aparecieron de forma progresiva a las 24-48 horas de hacerse un tatuaje a nivel de dorso del pie.

La paciente recibió tratamiento con corticoides y nitrato de plata tópicos. En una biopsia cutánea se aisló Pseudomonas aeruginosa sensible a quinolonas, cefepine, aminoglucósidos, carbapenemes, piperacilina-tazobactam y colistina. Se prescribió 
ciprofloxacino oral $500 \mathrm{mg} / 12 \mathrm{~h}$ y posteriormente $750 \mathrm{mg} / 12 \mathrm{~h}$ durante 15 días, sin mejoría y con progresiva afectación de la movilidad. No había presentado fiebre ni escalofríos acompañantes.

En el examen físico presentaba una ulceración de unos $10 \mathrm{~mm}$ de diámetro, con bordes eritematosos, macerados y tejido necrosado sin supuración activa. Figura 1. No presentaba aumento de temperatura local. Mostraba dolor a la flexo extensión pasiva y activa.

Figura 1: Estados evolutivos de la lesión.

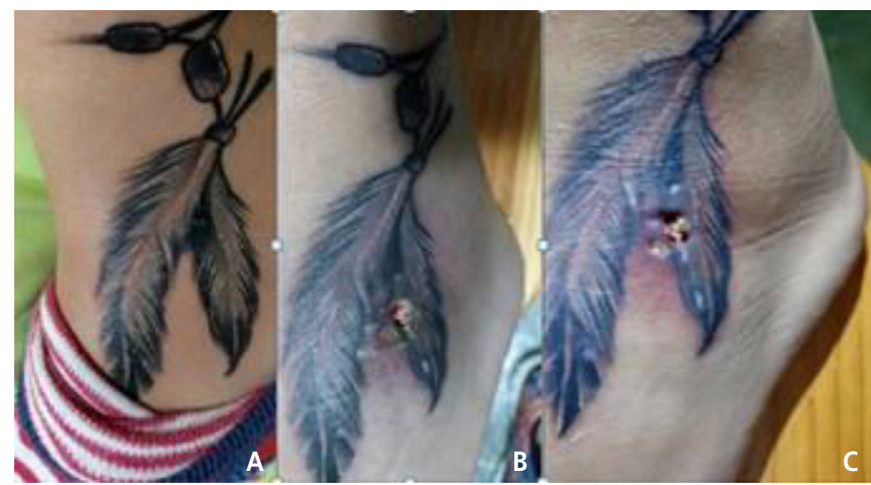

a) A los pocos días de realizarse el tatuaje; b) Al mes; c) A los dos meses, en la consulta de urgencias.

Figura 2: Secuencia T1. La flecha señala un engrosamiento del tendón extensor común de los dedos y signos inflamatorios en el tejido celular subcutáneo.

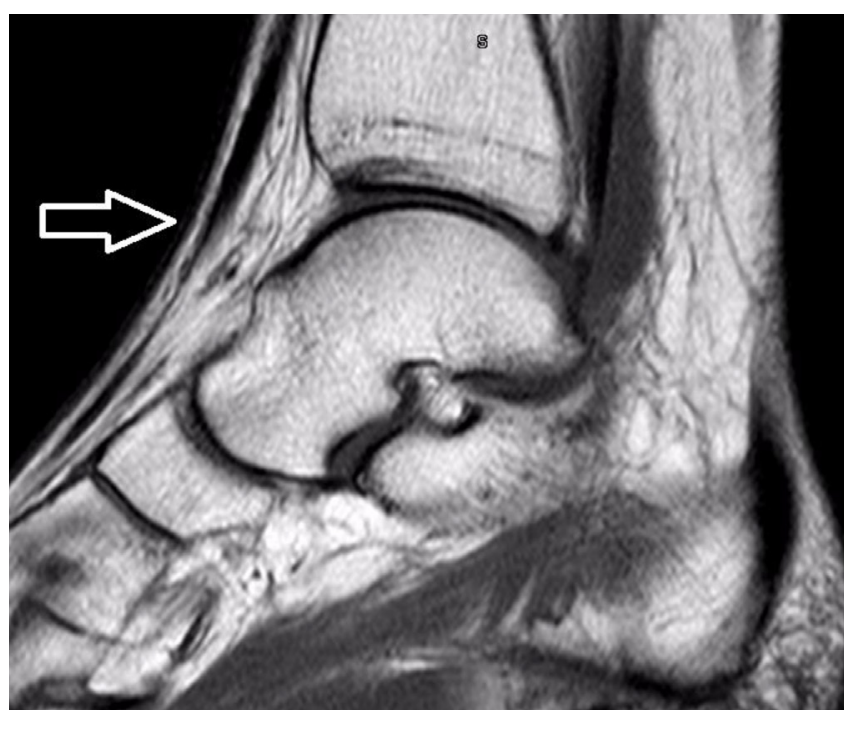

Una RMN reciente mostraba hallazgos sugestivos de celulitis y de un pequeño absceso en el tejido celular subcutáneo superficial en la región lateral del mediopié ( $9 \times 6 \times 6 \mathrm{~mm})$, coincidiendo con el defecto cutáneo. El tendón extensor común de los dedos mostraba un engrosamiento focal y el tejido celular subcutáneo que lo rodeaba presentaba tractos fibrótico-cicatriciales y edema. Figura 2. Se decidió ingreso hospitalario con tratamiento antibiótico intravenoso (piperacilina-tazobactam) durante 15 días.

\section{Discusión}

En nuestro caso, describimos una paciente inmunocompetente que desarrolla una tenosinovitis por Pseudomonas aeruginosa probablemente secundaria a la realización de un tatuaje.

La tenosinovitis afecta con mayor frecuencia a dedos de la mano o la muñeca. [5] En el pie afecta más frecuentemente a la región de los flexores plantares, siendo muy rara la presentación en la región extensora. [1, 2, 3]

El diagnóstico de la tenosinovitis se realiza con la exploración física y las pruebas de imagen (radiografía simple, ecografía, TAC, RMN). [7] En nuestro paciente se aisló Pseudomonas aeruginosa en la biopsia cutánea y se confirmó el diagnóstico de tenosinovitis mediante RMN.

El diagnóstico diferencial se debe hacer en primer lugar con la celulitis del dorso del pie, para lo cual es muy útil la realización de una ecografía con sonda lineal a pie de cama. [6]

Se han descrito múltiples complicaciones tras la realización de tatuajes. Entre las complicaciones infecciosas destacan infecciones de la piel como impétigo, erisipela, celulitis y complicaciones sistémicas como endocarditis, shock séptico y fracaso multiorgánico. Los microorganismos generalmente implicados son el S. aureus y Pseudomonas sp. [7] La Pseudomonas aeruginosa es un microorganismo común en el entorno ambiental, especialmente en el agua. [8]

Respecto a las complicaciones inflamatorias se han descrito reacciones liquenoides, espongióticas, granulomatosas, pseudolinfomas y pseudoepiteliomas. [9]

El tratamiento se basa fundamentalmente en antibióticos intravenosos y en el desbridamiento quirúrgico [10].

\section{Conclusiones}

La tenosinovitis infecciosa asociada a tatuaje, aunque es infrecuente debe sospecharse ante la evolución tórpida tras tratamiento tópico adecuado. Ante la confirmación de tenosinotivis infecciosa es mandatorio el tratamiento con antibióticos parenterales y la evacuación. 


\section{Referencias}

1. Tung $\mathrm{C}-\mathrm{H}$, Chen $\mathrm{Y}-\mathrm{H}$, Lan HHC, Hsieh T-Y, Chen D-Y, Lan J-L. Diagnosis of plant thorn synovitis by high-resolution ultrasonography: a case report and literature review. Clin Rheumatol. 2007;26:849-51.

2. Bruce WD, Christofersen MR, Phillips DL. Stenosing tenosynovitis and impin gement of the peroneal tendons associated with hypertrophy of the peroneal tubercle. Foot Ankle Int. 1999; 20:464-7.

3. Muramatsu K, Mine T, Ichihara K. Atypical tenosynovial giant cell tumor of the extensor hallucis longus tendon. J Am Podiatr Med Assoc. 2006 Jul-Aug; 96(4):359-61.

4. Small LN, Ross JJ. Suppurative tenosynovitis and septic bursitis. Infect Dis Clin N Am. 2005; 19(4):991-1005.

5. Tsai E, Failla JM. Hand infections in the trauma patient. Hand Clin. 1999; 15(2):373-86.

6. Guillén Astete CA, Rodríguez García A, Prieto Morales M, Zea Mendoza A. Infectious tenosynovitis of the foot extensors. Reumatol Clin. 2014 Jan-Feb; 10(1):56-7.

7. Dieckmann R, Boone I, Brockmann SO, Hammerl JA, KolbMäurer A, Goebeler M, Luch A, Al Dahouk S. The Risk of Bacterial Infection After Tattooing. Dtsch Arztebl Int. 2016 Oct 7; 113(40):665-671.

8. Favero MS, Carson LA, Bond WW, Petersen NJ. Pseudomonas aeruginosa: growth in distilled water from hospitals. Science $1971 ; 173: 836$.

9. Wood A, Hamilton SA, Wallace WA, Biswas A. Necrobiotic granulomatous tattoo reaction: report of an unusual case showing features of both necrobiosis lipoidica and granuloma annulare patterns. Am J Dermatopathol. 2014 Aug; 36(8):e152-5.

10. Hyatt BT, Bagg MR. Flexor Tenosynovitis. Orthop Clin North Am. 2017 Apr; 48 (2):217-227.

\section{Publique en Acta Reumatológica}

Acta Reumatológica es una revista que tiene por fin la difusión de estudios clínicos relacionados con aspectos prácticos del diagnóstico, tratamiento y seguimiento de pacientes con patología reumatológica, de estudios epidemiológicos relacionados con patología inflamatoria y musculoesquelética de presentación común o infrecuente en la práctica clínica tanto en población adulta como pediátrica, de casos clínicos de patología poco habitual o de presentaciones inhabituales de patología frecuente, de imágenes didácticas e ilustrativas en reumatología y del estado actual e innovación en la formación especializada en reumatología. 